\title{
Oral Sustained Release Tablets of Zidovudine Using Binary Blends of Natural and Synthetic Polymers
}

\author{
Martins Emeje, ${ }^{* a, e}$ Olajide Olaleye,${ }^{a}$ Christiana Isimi,${ }^{a}$ Joseph Fortunak, ${ }^{b}$ Stephen Byrn,${ }^{c}$ \\ Olobayo Kunle, ${ }^{a}$ and Sabinus Ofoefule ${ }^{d}$ \\ ${ }^{a}$ Department of Pharmaceutical Technology and Raw Materials Development, National Institute for Pharmaceutical \\ Research and Development; Garki-900001, Abuja, Nigeria: ${ }^{b}$ Department of Chemistry, Howard University; Washington, \\ D.C. 20059, U.S.A.: ' Department of Medicinal Chemistry and Physical Pharmacy, Purdue University; IN 47907-2091, \\ U.S.A.: ${ }^{d}$ Department of Pharmaceutical Technology and Industrial Pharmacy University of Nigeria; Nsukka-400001, \\ Enugu State, Nigeria: and ${ }^{e}$ Department of Molecular Biology and Biotechnology, Tezpur University; Tezpur-784028, \\ Assam, India. Received February 13, 2009; accepted June 21, 2010
}

Oral sustained release matrix tablets of zidovudine (ZDV) were prepared using different types, proportions and blends of carbopol 71G (C71) and a plant gum obtained from Abelmoschus esculentus (AEG). The effect of various formulation factors like polymer proportion, polymer type and $\mathrm{pH}$ of the dissolution medium on the in vitro release of the drug was studied, using the half change technique, in $900 \mathrm{ml}$ of dissolution medium, at 100 rpm. Release kinetics were analyzed using Zero-order, Higuchi's square-root and Ritger-Peppas' empirical equations. In vitro release performance as revealed by the time taken for $70 \%$ of the drug to be released $\left(t_{70 \%}\right)$, showed that the release rate decreased with increase in polymer proportion. Matrix tablets containing 10 and 20\% AEG were found to exhibit immediate-release characteristics. Matrix tablets containing 30\% AEG showed $t_{70 \%}$ value of $204 \mathrm{~min}$ and extended the release up to $\mathbf{5} \mathrm{h}$, while matrix tablets containing $30 \%$ carbopol showed $t_{70 \%}$ value of $234 \mathrm{~min}$ and extended the release up to $6 \mathrm{~h}$. Three blends of AEG and C71 at the ratio of 1:2, $2: 1$ and $1: 3$ showed $t_{70 \%}$ values of 132, 312 and 102 min respectively and extended the release up to $8 \mathrm{~h}$. Mathematical analysis of the release kinetics indicated that the nature of drug release from the matrix tablets followed Fickian and anomalous release. Drug release from matrix tablets of zidovudine containing blends of AEG and C71 demonstrates the advantage of blending a natural and synthetic polymer over single polymer use.

Key words sustained release; matrix tablet; zidovudine; Abelmoschus esculentus; polyacrylic acid polymer

AIDS is considered to be an epidemic and about 38.0 million adults and 2.3 million children were living with human immunodeficiency virus (HIV) at the end of 2005. ${ }^{1)}$ The annual number of AIDS deaths can be expected to increase for many years to come, unless more effective and patient compliant anti-retroviral medications are available and at affordable prices. ${ }^{2)}$ The major drawbacks of antiretroviral drugs for the treatment of AIDS are their adverse side effects during long-term therapy, poor patient compliance and huge cost of the therapy. ${ }^{3,4)}$ Zidovudine (ZDV) is a potent antiviral drug used in the treatment of AIDS. Its oral bioavailability is reduced to as low as $63 \%$ (1) due to first pass hepatic glucuronidation and a high clearance. It has a short biologic half-life of 0.5 to $3 \mathrm{~h}^{5-8)}$ necessitating frequent administration of large doses $(200 \mathrm{mg}$ every $4-6 \mathrm{~h}$ or $300 \mathrm{mg}$ twice daily) to maintain therapeutic drug levels. Treatment of AIDS using conventional formulations of ZDV is found to have many drawbacks such as frequent development of anemia, leucopenia and accumulation of the drug in multi-dose therapy. These side effects are dose-dependent and a reduction of the total administered dose reduces the severity of the toxicity. Poor patient compliance and high cost are also common drawbacks. ${ }^{9-11)}$ Sustained release (SR) formulations of ZDV can overcome some of these problems. For many reasons, oral drug delivery continues to be the preferred route of drug administration. It is the oldest and the commonest mode of drug administration as it is safer, more convenient, does not need assistance, non-invasive, often painless, the medicament need not be sterile and so is cheaper. ${ }^{12)}$ The use of hydrophilic matrices in achieving this is increasingly becoming important especially in controlling the release rate of drugs from solid dosage forms. ${ }^{13-16)}$ These systems are attractive approaches from economic as well as process development view point. ${ }^{16-19)}$ A sustained release matrix tablet consists of a compressed compact containing a mixture of one or more bioactive agent(s) with one or more matrix former(s), which retards drug release. ${ }^{19)}$ Hydrophilic swellable polymers have widely been used to control the release of drugs from matrix tablet formulations in the last three decades ${ }^{13,14,20)}$ and the increasing need for suitable polymers to achieve the desired drug release profile makes pharmaceutical research to widely screen a large variety of both synthetic and natural polymers which show drug release retarding ability. However, because of the cost of both synthesis of new polymeric materials and their safety, a new focus has been directed towards investigation of the use of polymer blends of pharmaceutically approved polymeric materials as matrix functional excipients to enhance single polymer performance. Carbopol polyacrylic acid polymers have demonstrated many useful performance properties in tablet applications. ${ }^{21-23)}$ They are useful at low levels $(1-3 \%)$ as binders and at higher levels (5-30\%), they achieve modified or even zero order controlled release of bioactives. Due to their extremely efficient thickening and gelling characteristics, carbopol resins have been widely used in various pharmaceutical applications including beads, gels and ointments. ${ }^{21)}$ In tablet formulations, carbomers are used as dry or wet binders and as a rate-controlling excipient. Carbomers have also been investigated in the preparation of sustained-release matrix beads, as enzyme inhibitors of intestinal proteases in peptidecontaining dosage forms, as a bioadhesive for a cervical patch and for intranasally administered microspheres, and 
in magnetic granules for site-specific drug delivery to the esophagus. $^{23)}$ Carbopol $71 \mathrm{G}$ is the newest polyacrylic acid derivative and literature survey reveal that very few reports exist on it, ${ }^{16)}$ Carbopol $71 \mathrm{G}$ is one member of the carbopol family of polymers that is suitable for use in oral dosage forms since it was polymerized in ethyl acetate, a relatively non toxic solvent. ${ }^{16}$ ) It is a water-swellabe high molecular weight polyacrylic acid. ${ }^{16}$ ) The release of the drug from the SR matrices is influenced by various formulation factors such as polymer viscosity, polymer particle size, drug to polymer ratio, drug solubility, drug particle size, compression force, tablet shape, formulation excipients, formulation additives, processing techniques and dissolution medium. ${ }^{16,24-35)}$ The drug release from polymer matrix can be due to disentanglement or diffusion, depending on the polymer molecular weight and the thickness of the diffusion boundary layer. ${ }^{35)}$ Several kinetic models have been proposed to describe the release characteristics of a drug from controlled release polymer matrix. The following three equations are currently in common use due to their simplicity and applicability. ${ }^{31)}$

Zero-order model equation:

$$
M_{t} / M_{\infty}=K_{\mathrm{O}} t
$$

Higuchi's square-root equation:

$$
M_{t} / M_{\infty}=K_{\mathrm{H}} t_{1 / 2}
$$

Ritger-Peppas' empirical equation:

$$
M_{t} / M_{\infty}=K_{t}^{n}
$$

Where $M_{t} / M_{\infty}$ is the fraction of drug released at any time $t$; $K_{\mathrm{O}}, K_{\mathrm{H}}$ and $K$ are release rate constants for Eqs. 1, 2 and 3 respectively. In Eq. 3, $n$ is the diffusional exponent indicative of mechanism of drug release. In case of tablets (which are of cylindrical shape), a value of $n \_0.45$ indicates Fickian or Case I release; $0.45 \_n \_0.89$ for non-Fickian or anomalous release; $n \_0.89$ for Case II release; and $n \_0.89$ indicates Super Case II release.

The plant Abelmoschus esculentus is a tall erect annual plant commonly known as 'Okra.' It is widely cultivated in most tropical countries. It can be grown year round and the gum obtained from its fruits is known for its viscous mucilaginous solution in water. This property has been utilized in the production of a plasma expander. ${ }^{31)}$ Abelmoschus esculentus gum (AEG) has also been used as suspending and emulsifying agents. ${ }^{32,33)}$ Recently, the binding and compaction characteristics ${ }^{34)}$ as well as the sustained release potential $^{35)}$ of the gum obtained from the plant were reported.

In the present study, we assess the effect of blending carbopol $71 \mathrm{G}$ with a natural gum; Abelmoschus esculentus on the rate and mechanism of release of Zidovudine from tablet matrices. The tablets were formulated by direct compression method and their physical and in vitro release characteristics were evaluated.

\section{MATERIALS AND METHODS}

Materials Abelmoschus esculentus gum (AEG) from the fresh fruits of Abelmoschus esculentus plant, was extracted and characterized as described elsewhere. Zidovudine and

\begin{tabular}{|c|c|c|c|c|c|}
\hline \multicolumn{2}{|l|}{$\begin{array}{c}\text { Batch } \\
\text { code/no. }\end{array}$} & \multirow{2}{*}{$\begin{array}{c}\text { Polymer } \\
\text { concentration }(\%) \\
10.0\end{array}$} & \multirow{2}{*}{$\begin{array}{l}\begin{array}{l}\mathrm{ZDV} \\
(\mathrm{mg})\end{array} \\
300.0\end{array}$} & \multirow{2}{*}{$\begin{array}{c}\begin{array}{c}\text { Cellactose } \\
(\mathrm{mg})\end{array} \\
70.0\end{array}$} & \multirow{2}{*}{$\begin{array}{c}\begin{array}{c}\text { Tablet weight } \\
(\mathrm{mg})\end{array} \\
400.0\end{array}$} \\
\hline AEG & 1 & & & & \\
\hline & 2 & 20.0 & 300.0 & 40.0 & 400.0 \\
\hline & 3 & 30.0 & 300.0 & 10.0 & 400.0 \\
\hline C71 & 4 & 10.0 & 300.0 & 70.0 & 400.0 \\
\hline & 5 & 20.0 & 300.0 & 40.0 & 400.0 \\
\hline & 6 & 30.0 & 300.0 & 10.0 & 400.0 \\
\hline $\begin{array}{c}\mathrm{AEG}+\mathrm{C} 71 \\
1: 1\end{array}$ & 7 & 30.0 & 300.0 & 10.0 & 400.0 \\
\hline $\begin{array}{c}\mathrm{AEG}+\mathrm{C} 71 \\
1: 2\end{array}$ & 8 & 30.0 & 300.0 & 10.0 & 400.0 \\
\hline $\begin{array}{c}\mathrm{AEG}+\mathrm{C} 71 \\
1: 3\end{array}$ & 9 & 30.0 & 300.0 & 10.0 & 400.0 \\
\hline $\begin{array}{c}\mathrm{AEG}+\mathrm{C} 71 \\
2: 1\end{array}$ & 10 & 30.0 & 300.0 & 10.0 & 400.0 \\
\hline $\begin{array}{c}\mathrm{AEG}+\mathrm{C} 71 \\
3: 1\end{array}$ & 11 & 30.0 & 300.0 & 10.0 & 400.0 \\
\hline
\end{tabular}
carbopol 71G (C71) were obtained as gifts from Rambaxy
Table 1. Composition of Matrix Tablets of Zidovudine

AEG (batches 1-3), matrix tablets containing 10, 20 and 30\% Abelmoschus esculentus gum respectively; $\mathrm{C} 71$ (batches 4-6), matrix tablets containing 10, 20 and 30\% carbopol $71 \mathrm{G}$ respectively; $\mathrm{AEG}+\mathrm{C} 71$ (batches 7-11) matrix tablets containing binary mixtures of Abelmoschus esculentus gum and carbopol $71 \mathrm{G}$ in ratio $1: 1,1: 2$, $1: 3,2: 1$ and $3: 1$ respectively.

Pharm. Plc and Noveon Plc, U.S.A., respectively. Cellactose (Sigma, U.K.). All other reagents used were of analytical grade.

Methods. Powder Characterization. Determination of Flow Parameters The bulk, tapped, true densities and angle of Repose were determined using standard methods. ${ }^{36)}$ Hausners Index

This was calculated as the ratio of tapped density to bulk density of the samples.

Compressibility Index $(\mathrm{C} \%)$

This was calculated using the equation:

compressibility $=[($ tapped density - bulk density $) /($ tapped density $)] \times 100$

Preparation of Matrix Tablets Matrix tablets of ZDV were prepared by direct compression method using cellactose and magnesium stearate as diluent and lubricant respectively. Ae and C71 gums were included in the formulations as single polymers and as binary blends in various proportions (Table 1). Ae gum of particle size $<250 \mu \mathrm{m}$ was mixed with ZDV $(<150 \mu \mathrm{m})$ and Cellactose $(<150 \mu \mathrm{m})$ in a blender (Braun, Germany) in all the formulations. The powder mixtures were mixed for 10 min using a tubular mixer (Karl kolb, D. 6072 Dreieich, Germany) and lubricated with $1.0 \%$ magnesium stearate for $5 \mathrm{~min}$ using the tubular mixer. The final blend was compressed using a single station tablet press (THP Shanghai, Tianxiang ad Chentai Pharmaceutical Machinery Co., Ltd., China) equipped with $10.5 \mathrm{~mm}$ punch and die set. Tablets weighing $400 \mathrm{mg}$ each and containing $300 \mathrm{mg}$ ZDV were compressed at $23.75 \mathrm{kN}$ and dwell time of $60 \mathrm{~s}$.

Tablet Properties The weight of all the tablets in each batch was determined using BD202 balance (Mettler Toledo, U.S.A.) while the dimensions (thickness and diameter) were determined using a micrometer screw gauge (Mitutoyo Corp., Tokyo, Japan) to the nearest $0.01 \mathrm{~mm}$. The mean values \pm S.D. of the tablet weight and dimensions were determined. The tablets were tested for their hardness using the Erweka hardness tester, drug content and release characteristics with a suitable number of tablets for each test. 
Tablet Thickness, Friability and Tensile Strength A Pharmatest model PTB-311 (Germany), apparatus was used to determine the tablet thickness and crushing strength. Crushing strength was examined by placing a tablet between a stationary and moving spindle. Force was applied by turning the moving spindle until the tablet cracked diametrically. Tablet tensile strength was calculated according to the method reported by Emeje et al. ${ }^{14)}$ The friability of the compacts was evaluated from the mass loss of 10 tablets tumbled for 100 revolutions $(25 \mathrm{rpm}$ for $4 \mathrm{~min}$ ) using a friabilator (Erweka, Germany).

Swelling Studies The method reported by Emeje et al. ${ }^{16)}$ was adopted for the study.

In Vitro Drug Release Studies The ability of matrix tablets of ZDV to remain intact in the physiological environment of the stomach and small intestine was assessed by conducting drug release studies using the half change technique: This mimics mouth to intestinal transit; drug release studies were carried out using USP dissolution rate apparatus (Apparatus $1,100 \mathrm{rpm}, 37^{\circ} \mathrm{C}$ ) for the first $2 \mathrm{~h}$ in $\mathrm{pH} 1.2$ simulated gastric fluid (SGF) without enzymes $(900 \mathrm{ml})$. Then the dissolution medium was changed to $\mathrm{pH} 7.4$ simulated intestinal fluid (SIF) without enzymes $(900 \mathrm{ml})$ and tested for drug release for the remaining $6 \mathrm{~h}$. Five milliliters aliquot of the dissolution medium were withdrawn at hourly intervals up to at least $8 \mathrm{~h}$. The withdrawn amount was replaced with an equal volume of fresh dissolution medium kept at $37^{\circ} \mathrm{C}$. The withdrawn samples were analyzed at $270 \mathrm{~nm}$ for ZDV content using a Shimadzu UV Spectrophotometer (Shimadzu, Japan). The data presented here is for quadruplicate determinations. For each dissolution profile, the release data was analyzed by fitting in the different kinetic equations to elucidate the release mechanism.

\section{RESULTS AND DISCUSSION}

Powder Properties The micromeritic properties of the different ZDV-polymer mixtures used are given in Table 2. There was no appreciable difference in the bulk and tapped densities of all the formulations. The true density measurement of the mixtures show that formulations containing $20 \%$ AEG (batch 2) had the lowest value while those contaning $30 \%$ C71G (batch 6) had the highest value. Low values of true density imply the presence of a comparatively higher number of possible enclosed voids. The results indicate that blending produced intermediate values, with neither too high nor too low values. The compressibility index (CI) is an indication of changes that occur in the packing arrangement while tapping the powder, and is a direct measure of the propensity of a powder to consolidate when undergoing vibration, shipping and handling. ${ }^{37)}$ Table 2 shows that this compressibility index was highest for batch 10 (containing $\mathrm{AEG} / \mathrm{C} 71$ at ratio $2: 1$ ) which expectedly had a low flow rate. Batch 4 (containing 10\% C71) with FR of $0.75 \mathrm{~g} / \mathrm{s}$ and a high CI $(26.67 \%)$ is indicative of poor flow. CI between $5-15 \%$ indicates excellent flow properties. Flow rate rather than $\mathrm{CI}$ is a direct measurement of powder flowability. ${ }^{24)}$ Generally, values of the angle of repose for all the formulations show that, the powders have fair flow potentials. Blending was also found to improve flow as indicated by the angle of repose of $\mathrm{AEG} / \mathrm{C} 71$ at $1: 2$ and $3: 1$. Formulations containing AEG (batches $1-3$ ) were less porous than those containing $\mathrm{C} 71$, while those containing blends of the two polymers (batches $7-9,11)$ were more porous than formulations containing AEG (Table 2). In general, porosity of the formulations containing C71 decreased with increasing polymer concentration, while the packing fraction for all formulations except those containing blends decreased with increasing polymer concentration, implying closer packing of the powder particles.

Pharmacotechnical Properties of the Tablets Tablets produced with either individual polymers or their blends had similar properties with the blends being better in some cases (Table 3). The tablets showed low weight variation and high degree of drug content uniformity indicating that, the direct compression procedure used in this study is an acceptable method for preparing good quality matrix tablets of ZDV.

Swelling Studies Image analysis during the swelling of the AEG-C71-ZDV matrices showed increase in both axial and radial dimensions (Tables 4,5 ). The swelling rate was observed from the percent normalized size increase which was calculated as the radial length increase with respect to the initial value (to avoid error due to "lens effect"). The results show that matrix swelling in SIF was higher than in SGF (Tables 4, 5). The differences in the swelling rates of the matrices, which were most significant in the first $30 \mathrm{~min}$, could be due to a different speed of medium penetration into the tablets. Such behavior may depend on a slower initial in-

Table 2. Micromeritic Properties of the Mixtures

\begin{tabular}{|c|c|c|c|c|c|c|c|c|c|}
\hline Batch & $\begin{array}{l}\text { Flow } \\
\text { rate } \\
(\mathrm{g} / \mathrm{s})\end{array}$ & $\begin{array}{l}\text { Angle of } \\
\text { repose } \\
\left(0^{\circ}\right)\end{array}$ & $\begin{array}{c}\text { Bulk } \\
\text { density } \\
(\mathrm{g} / \mathrm{ml})\end{array}$ & $\begin{array}{l}\text { Tapped } \\
\text { density } \\
(\mathrm{g} / \mathrm{ml})\end{array}$ & $\begin{array}{c}\text { True } \\
\text { density } \\
(\mathrm{g} / \mathrm{ml})\end{array}$ & $\begin{array}{l}\text { Hausner's } \\
\text { ratio }\end{array}$ & $\begin{array}{c}\text { Carr's } \\
\text { index } \\
(\%)\end{array}$ & $\begin{array}{c}\text { Powder } \\
\text { porosity } \\
(\%)\end{array}$ & $\begin{array}{l}\text { Packing } \\
\text { fraction }\end{array}$ \\
\hline 1 & 1.00 & 26.57 & 0.42 & 0.55 & 1.35 & 1.31 & 23.64 & 68.89 & 0.31 \\
\hline 2 & 1.00 & 30.02 & 0.42 & 0.56 & 0.80 & 1.33 & 14.00 & 47.50 & 0.05 \\
\hline 3 & 1.00 & 26.57 & 0.39 & 0.53 & 1.28 & 1.36 & 26.42 & 69.53 & 0.03 \\
\hline 4 & 0.75 & 26.57 & 0.44 & 0.60 & 1.56 & 1.36 & 26.67 & 71.79 & 0.28 \\
\hline 5 & 0.60 & 28.61 & 0.44 & 0.60 & 2.01 & 1.36 & 26.67 & 78.11 & 0.22 \\
\hline 6 & 0.51 & 28.61 & 0.41 & 0.56 & 2.52 & 1.37 & 26.79 & 83.73 & 0.16 \\
\hline 7 & 0.38 & 31.16 & 0.41 & 0.58 & 1.88 & 1.41 & 29.31 & 78.19 & 0.22 \\
\hline 8 & 0.30 & 24.44 & 0.40 & 0.57 & 1.68 & 1.43 & 29.82 & 76.19 & 0.24 \\
\hline 9 & 0.27 & 26.57 & 0.41 & 0.57 & 1.65 & 1.39 & 28.07 & 75.15 & 0.25 \\
\hline 10 & 0.33 & 29.48 & 0.38 & 0.58 & 1.22 & 1.53 & 34.48 & 68.85 & 0.31 \\
\hline 11 & 0.60 & 23.96 & 0.39 & 0.56 & 1.48 & 1.44 & 30.36 & 73.65 & 0.26 \\
\hline
\end{tabular}

Batches $1-3$, matrix tablets containing 10, 20 and 30\% Abelmoschus esculentus gum respectively; batches $4-6$, matrix tablets containing 10,20 and $30 \%$ carbopol $71 \mathrm{G}$ respectively; batches 7-11, matrix tablets containing binary mixtures of Abelmoschus esculentus gum and carbopol 71G in ratio $1: 1,1: 2,1: 3,2: 1$ and $3: 1$ respectively. 
Table 3. Some Mechanical Properties of ZDV Tablets

\begin{tabular}{|c|c|c|c|c|c|c|}
\hline Batch & Thickness (mm) & Diameter (mm) & Weight (g) & Hardness (kgf) & Friability (\%) & $t_{70 \%}(\min )$ \\
\hline 1 & $3.01 \pm 0.04$ & $10.08 \pm 0.06$ & $0.275 \pm 0.005$ & $24.13 \pm 1.79$ & 1.79 & 42 \\
\hline 2 & $3.10 \pm 0.10$ & $10.04 \pm 0.03$ & $0.275 \pm 0.008$ & $22.67 \pm 4.93$ & 3.57 & 42 \\
\hline 3 & $3.04 \pm 0.03$ & $10.04 \pm 0.02$ & $0.278 \pm 0.007$ & $22.07 \pm 2.95$ & 1.79 & 204 \\
\hline 4 & $2.97 \pm 0.05$ & $10.04 \pm 0.02$ & $0.271 \pm 0.006$ & $31.87 \pm 1.01$ & 0.00 & 240 \\
\hline 5 & $3.01 \pm 0.04$ & $10.04 \pm 0.02$ & $0.277 \pm 0.007$ & $33.33 \pm 1.45$ & 1.82 & 258 \\
\hline 6 & $2.95 \pm 0.07$ & $10.03 \pm 0.03$ & $0.269 \pm 0.012$ & $32.27 \pm 1.81$ & 1.85 & 234 \\
\hline 7 & $3.02 \pm 0.02$ & $10.02 \pm 0.02$ & $0.274 \pm 0.005$ & $33.13 \pm 1.44$ & 1.79 & 96 \\
\hline 8 & $3.01 \pm 0.06$ & $10.02 \pm 0.02$ & $0.278 \pm 0.008$ & $31.60 \pm 0.20$ & 0.00 & 132 \\
\hline 9 & $2.99 \pm 0.05$ & $10.03 \pm 0.02$ & $0.274 \pm 0.005$ & $30.87 \pm 0.70$ & 1.82 & 102 \\
\hline 10 & $3.02 \pm 0.03$ & $10.02 \pm 0.02$ & $0.280 \pm 0.005$ & $30.93 \pm 0.61$ & 0.00 & 312 \\
\hline 11 & $3.02 \pm 0.03$ & $10.03 \pm 0.03$ & $0.280 \pm 0.007$ & $30.60 \pm 0.72$ & 0.00 & 228 \\
\hline
\end{tabular}

Batches $1-3$, matrix tablets containing 10,20 and 30\% Abelmoschus esculentus gum respectively; batches $4-6$, matrix tablets containing 10,20 and $30 \%$ carbopol $71 \mathrm{G}$ respectively; batches 7-11, matrix tablets containing binary mixtures of Abelmoschus esculentus gum and carbopol $71 \mathrm{G}$ in ratio $1: 1,1: 2,1: 3,2: 1$ and $3: 1$ respectively.

Table 4. Effect of Polymer Type, Concentration and Blends on the Axial Expansion of ZDV Matrices in SGF

\begin{tabular}{|c|c|c|c|c|c|c|c|c|c|c|}
\hline \multirow{2}{*}{ Batch/time (h) } & \multicolumn{10}{|c|}{ Tablet diameter $(\mathrm{mm})$} \\
\hline & 0 & 1 & 2 & 3 & 4 & 5 & 6 & 7 & 8 & 24 \\
\hline 1 & 1.0 & 2.5 & 2.6 & 2.9 & 2.9 & 2.9 & 2.9 & 2.9 & 2.9 & 2.9 \\
\hline 2 & 1.0 & 2.0 & 3.0 & 3.1 & 3.2 & 3.2 & 3.2 & 3.2 & 3.2 & 3.2 \\
\hline 3 & 1.0 & 1.7 & 1.9 & 2.0 & 2.0 & 2.0 & 2.0 & 2.1 & 2.1 & 2.3 \\
\hline 4 & 1.0 & 1.2 & 1.3 & 1.4 & 1.5 & 1.5 & 1.5 & 1.5 & 1.5 & 1.5 \\
\hline 5 & 1.0 & 1.3 & 1.4 & 1.5 & 1.6 & 1.6 & 1.6 & 1.6 & 1.6 & 1.8 \\
\hline 6 & 1.0 & 1.3 & 1.4 & 1.7 & 1.7 & 1.7 & 1.7 & 1.7 & 1.7 & 2.0 \\
\hline 7 & 1.0 & 1.1 & 1.2 & 1.3 & 1.3 & 1.3 & 1.5 & 1.5 & 1.5 & 1.7 \\
\hline 8 & 1.0 & 1.1 & 1.3 & 1.4 & 1.4 & 1.4 & 1.5 & 1.5 & 1.5 & 1.7 \\
\hline 9 & 1.0 & 1.1 & 1.3 & 1.4 & 1.4 & 1.4 & 1.6 & 1.6 & 1.6 & 1.8 \\
\hline 10 & 1.0 & 1.1 & 1.2 & 1.4 & 1.4 & 1.4 & 1.5 & 1.5 & 1.5 & 1.7 \\
\hline 11 & 1.0 & 1.1 & 1.3 & 1.4 & 1.4 & 1.4 & 1.5 & 1.5 & 1.5 & 1.8 \\
\hline
\end{tabular}

Batches 1-3, matrix tablets containing 10, 20 and 30\% Abelmoschus esculentus gum respectively; batches $4-6$, matrix tablets containing 10 , 20 and $30 \%$ carbopol $71 \mathrm{G}$ respectively; batches 7-11, matrix tablets containing binary mixtures of Abelmoschus esculentus gum and carbopol $71 \mathrm{G}$ in ratio $1: 1,1: 2,1: 3,2: 1$ and $3: 1$ respectively.

Table 5. Effect of Polymer Type, Concentration and Blends on the Axial Expansion of ZDV Matrices in SIF

\begin{tabular}{|c|c|c|c|c|c|c|c|c|c|c|}
\hline \multirow{2}{*}{ Batch/time (h) } & \multicolumn{10}{|c|}{ Tablet diameter (mm) } \\
\hline & 0 & 1 & 2 & 3 & 4 & 5 & 6 & 7 & 8 & 24 \\
\hline 1 & 1.0 & 4.0 & 4.0 & 4.0 & 4.0 & 4.0 & 4.0 & 4.0 & 4.0 & 4.0 \\
\hline 2 & 1.0 & 1.8 & 1.8 & 1.8 & 1.8 & 1.8 & 1.8 & 1.8 & 1.8 & 2.3 \\
\hline 3 & 1.0 & 1.3 & 1.4 & 1.4 & 1.5 & 1.5 & 1.5 & 1.5 & 1.5 & 2.2 \\
\hline 4 & 1.0 & 1.1 & 1.3 & 1.3 & 1.5 & 1.4 & 1.5 & 1.5 & 2.0 & - \\
\hline 5 & 1.0 & 1.2 & 1.3 & 1.3 & 1.3 & 1.3 & 1.5 & 1.5 & 1.7 & - \\
\hline 6 & 1.0 & 1.1 & 1.3 & 1.3 & 1.3 & 1.3 & 1.4 & 1.5 & 1.7 & - \\
\hline 7 & 1.0 & 1.2 & 1.4 & 1.6 & 1.6 & 1.6 & 1.7 & 1.8 & 2.0 & 4.4 \\
\hline 8 & 1.0 & 1.2 & 1.4 & 1.5 & 1.5 & 1.5 & 1.6 & 1.7 & 1.9 & 4.2 \\
\hline 9 & 1.0 & 1.2 & 1.4 & 1.5 & 1.5 & 1.5 & 1.6 & 1.7 & 1.8 & 6.5 \\
\hline 10 & 1.0 & 1.3 & 1.4 & 1.5 & 1.5 & 1.5 & 1.6 & 1.7 & 1.8 & 2.5 \\
\hline 11 & 1.0 & 1.3 & 1.4 & 1.5 & 1.5 & 1.5 & 1.6 & 1.7 & 1.8 & 2.5 \\
\hline
\end{tabular}

Batches 1-3, matrix tablets containing 10, 20 and 30\% Abelmoschus esculentus gum respectively; batches 4 - 6 , matrix tablets containing 10 , 20 and $30 \%$ carbopol $71 \mathrm{G}$ respectively; batches 7-11, matrix tablets containing binary mixtures of Abelmoschus esculentus gum and carbopol 71G in ratio $1: 1,1: 2,1: 3,2: 1$ and $3: 1$ respectively.

teraction between the medium and the polymer-drug system and could equally account for the initial rapid release observed during dissolution. After the initial period, the formation of a less porous and stronger gel layer, which limits fluid uptake, could increase the diffusion pathway and decrease gel erosion. ${ }^{16)}$ Irrespective of the dissolution medium, blending practically resulted in attenuated swelling of the individual polymers, with the blends having reduced hydration and spread of the polymer. AEG tablets were observed to swell more rapidly than both carbopol and blend tablets.
Tablets containing AEG (batches 1-3) lost their structural integrity after $2 \mathrm{~h}$ in SGF, while those containing C71 alone and blends of AEG/C71 (batches 4-11) were intact even after $12 \mathrm{~h}$. In SIF however, only the formulation containing 10\% AEG (batch 1) lost its integrity and this in just $1 \mathrm{~h}$ with the other batches remaining up to $24 \mathrm{~h}$.

Characterization of Bulk Drug and Effect of Various Polymer Blends The DSC thermograms of ZDV and its solid admixture with the polymers are shown in Figs. $4 a, b$ respectively. Both ZDV alone and its admixture showed a 


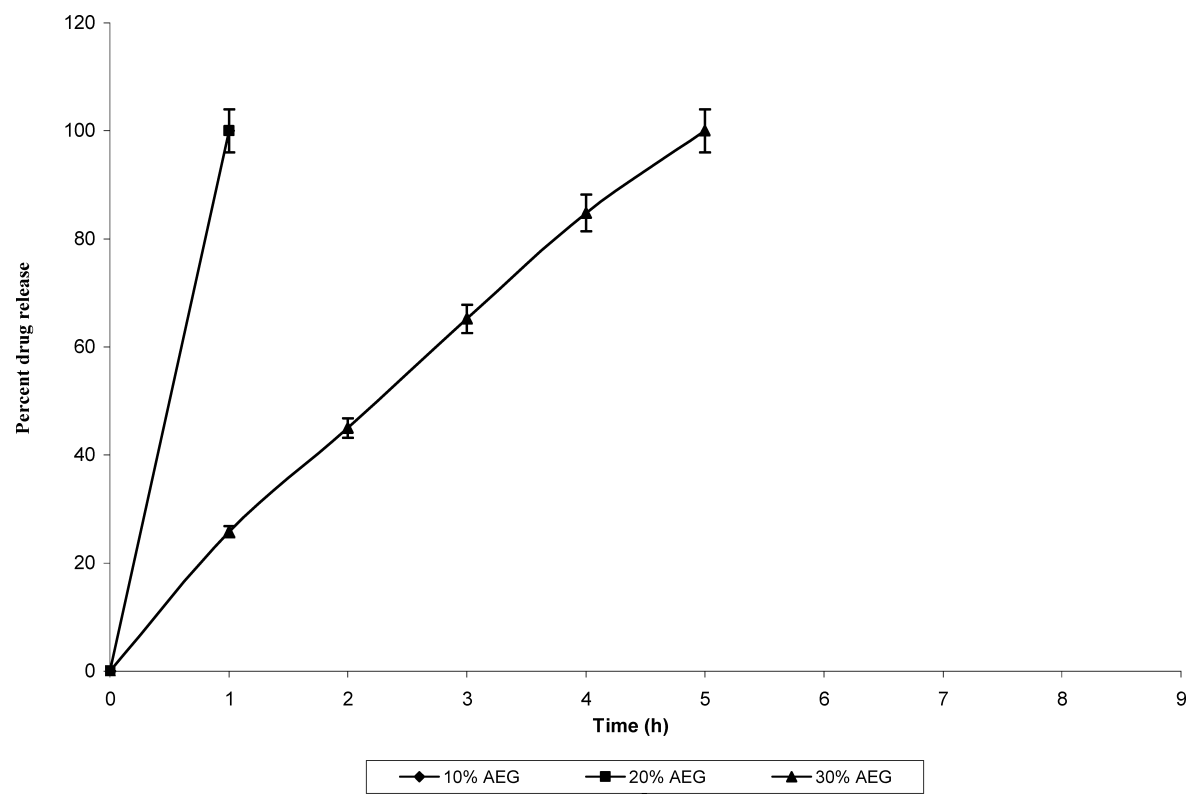

Fig. 1. Effect of Polymer Concentration on the Release Profile of ZDV from AEG Tablet Matrix Using the Half Change Technique

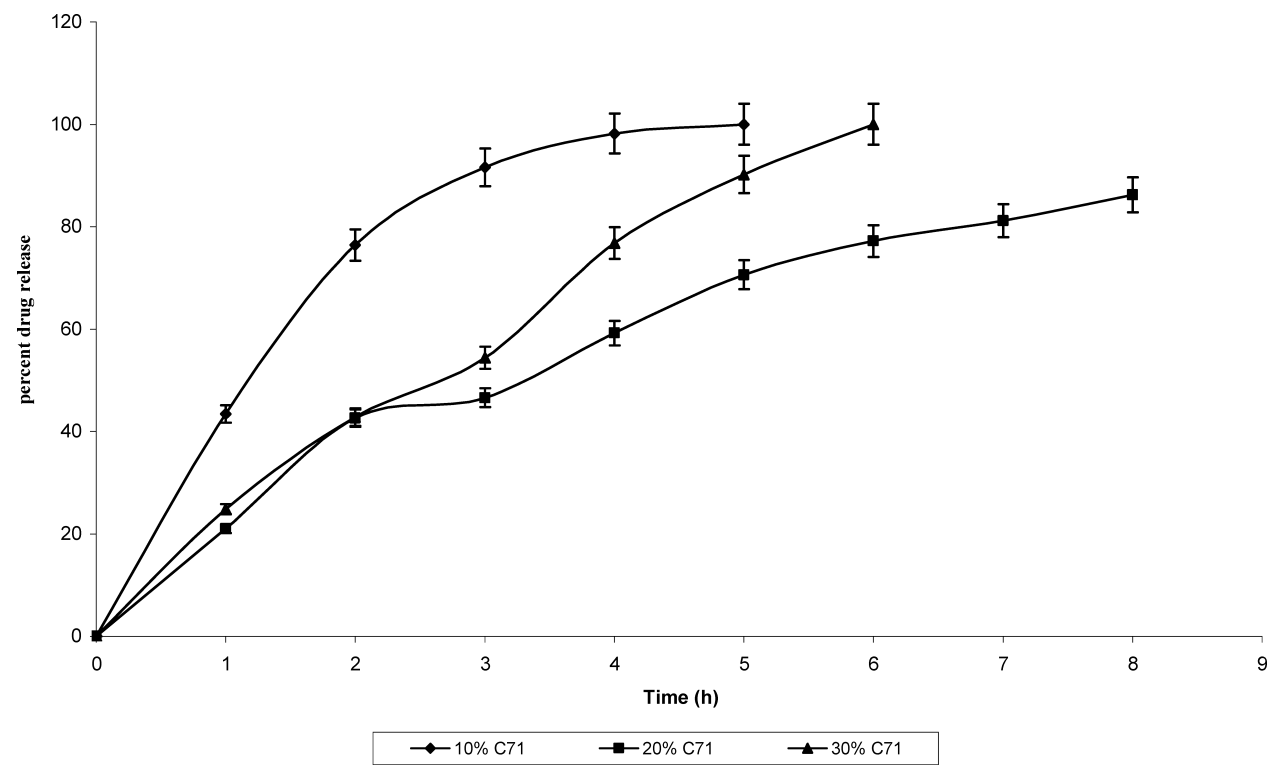

Fig. 2. Effect of Polymer Concentration on the Release Profile of ZDV from Carbopol 71 Tablet Matrix Using the Half Change Technique

sharp melting endothermic peak indicating that ZDV is unaffected by the polymers used in the preparation of the matrix tablets.

Physical Characterization of the Matrix Tablets The physical appearance, tablet hardness, friability, weight variation and drug content uniformity of all tablet formulations were found to be satisfactory (Table 3 ). The hardness values for tablets containing carbopol alone were not significantly different from those containing polymer blends. However, hardness values for AEG containing tablets were slightly less than those with AEG/C71G polymer blends. The result of friability test showed that those containing blends were less friable than those containing individual polymers. The manufactured tablets also showed low weight variation and a high degree of content uniformity, indicating that the direct compression method is an acceptable method for preparing good quality matrix tablets of ZDV.

In Vitro Drug Release Studies Dissolution test results (Fig. 1) show that $10-20 \%$ AEG was not effective in sustaining ZDV release from the matrix tablets with the tablets releasing $100 \%$ of their content within $1 \mathrm{~h}$ (Fig. 1). This is an indication that lower concentration of AEG could serve as binder in immediate release solid dosage formulations. Increasing the concentration of AEG to $30 \%$ significantly extended the release of ZDV from 42 to $200 \mathrm{~min}$ (Fig. 1, Table 3). With the carbopol matrices, drug release decreased as the proportion of the polymer increased from 10 to $30 \%$ (Fig. 2). The effect of polymer blends on drug dissolution is shown in Fig. 3. Tablets formulated with 30\% AEG and C71G individually released $70 \%$ of their drug content in 204 and 234 min respectively. AEG and $\mathrm{C} 71 \mathrm{G}$ were blended at five different ratios: $1: 1,1: 2,2: 1,1: 3$, and $3: 1$. The re- 


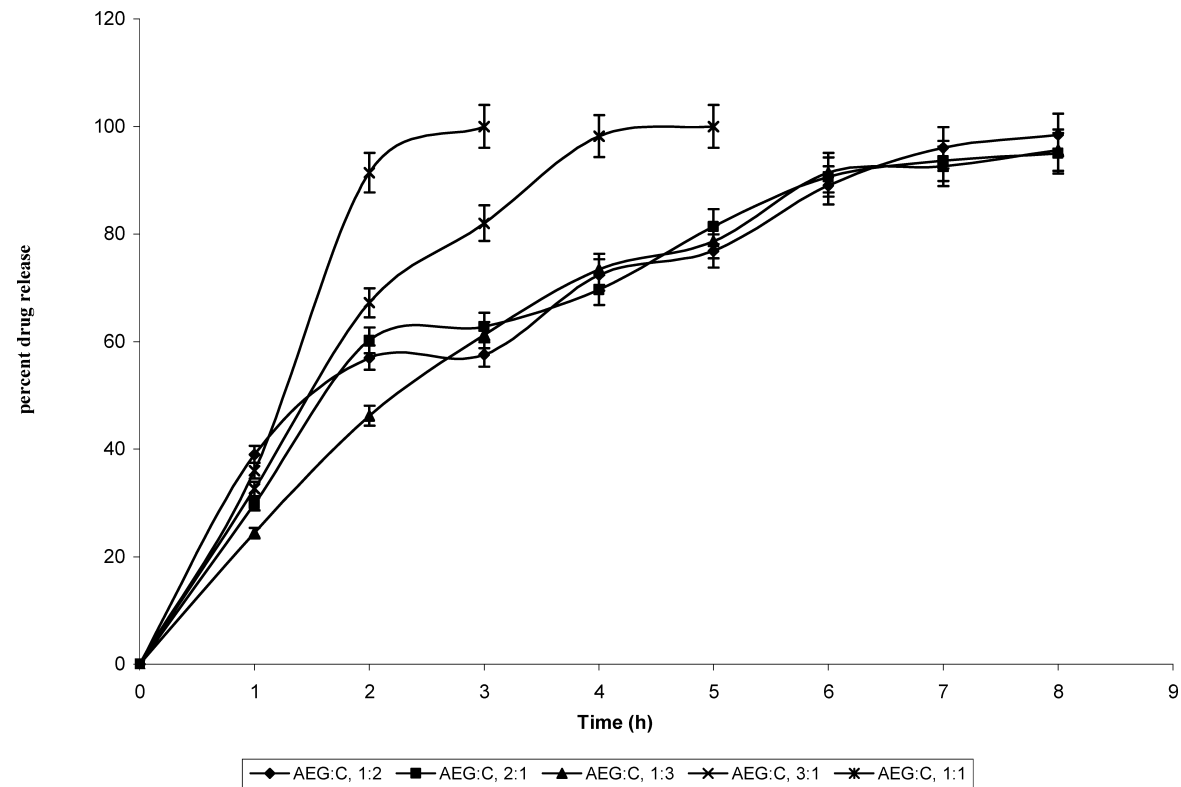

Fig. 3. Effect of Binary Blends of AEG and Carbopol 71 on the Release of ZDV from Tablet Matrices Using the Half Change Technique
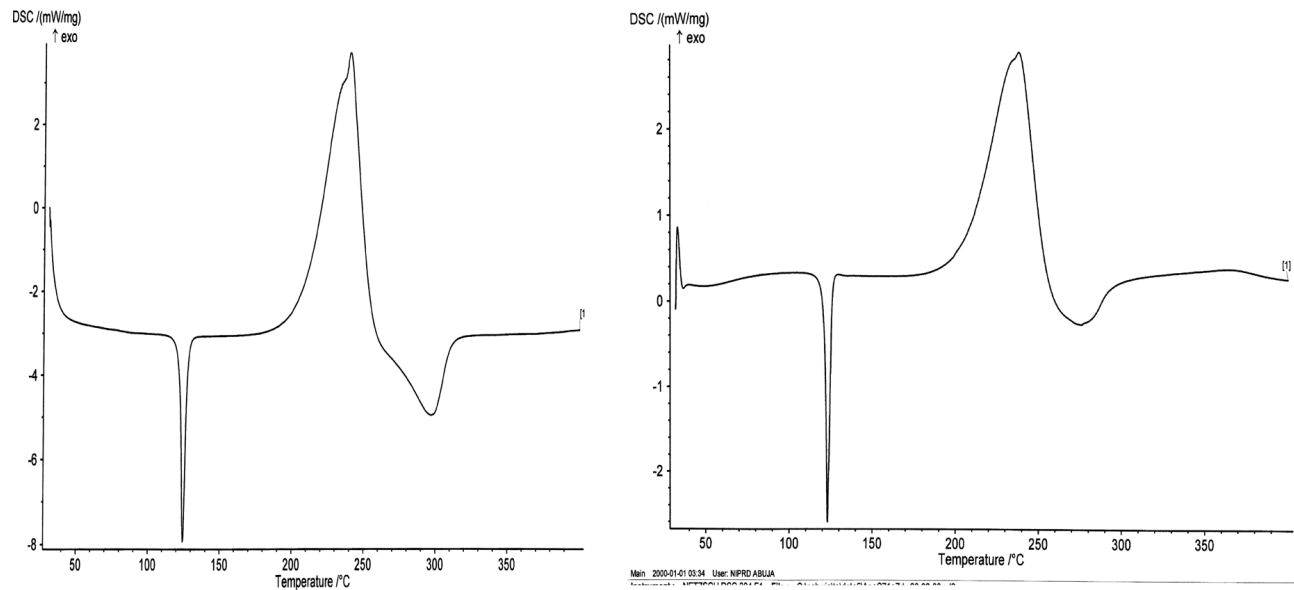

Fig. 4. DSC Thermograms of Pure ZDV (a) and Mixture of ZDV+C71+AEG (b)

Table 6. Release Kinetic Parameters of Sustained Release Matrix Tablets of Zidovudine

\begin{tabular}{|c|c|c|c|c|c|c|c|}
\hline \multirow[b]{2}{*}{ Batches } & \multicolumn{2}{|c|}{ Zero order equation } & \multicolumn{3}{|c|}{ Higuchi's square root equation } & \multicolumn{2}{|c|}{ Ritger-Peppas, equation } \\
\hline & $r$ & $k$ & $r$ & $k$ & $r$ & $k$ & $n$ \\
\hline 1 & NA & NA & NA & NA & NA & NA & NA \\
\hline 2 & NA & NA & NA & NA & NA & NA & NA \\
\hline 3 & 0.99 & 19.92 & 0.99 & 0.95 & 0.99 & 1.40 & 0.86 \\
\hline 4 & 0.85 & 19.42 & 0.98 & 1.41 & 0.99 & 1.59 & 0.44 \\
\hline 5 & 0.94 & 10.31 & 0.93 & 1.33 & 0.97 & 1.53 & 0.53 \\
\hline 6 & 0.99 & 16.60 & 0.94 & 2.53 & 0.98 & 1.44 & 0.65 \\
\hline 7 & 0.89 & 10.80 & 0.93 & 0.98 & 0.96 & 1.59 & 0.97 \\
\hline 8 & 0.87 & 10.85 & 0.94 & 1.20 & 0.97 & 1.55 & 0.71 \\
\hline 9 & 0.91 & 11.58 & 0.92 & 1.42 & 0.96 & 1.68 & 0.52 \\
\hline 10 & 0.94 & 35.54 & 0.96 & 1.11 & 0.99 & 1.36 & 0.67 \\
\hline 11 & 0.92 & 20.33 & 0.99 & 1.00 & 1.00 & 1.39 & 0.80 \\
\hline
\end{tabular}

NA, parameter not determined; $n$, exponential coefficient; $r$ and $k$, correlation coefficient and release rate constant respectively. Batches $1-3$, matrix tablets containing 10,20 and $30 \%$ Abelmoschus esculentus gum respectively; batches $4-6$, matrix tablets containing 10, 20 and $30 \%$ carbopol $71 \mathrm{G}$ respectively; batches 7 - 11 , matrix tablets containing binary mixtures of Abelmoschus esculentus gum and carbopol $71 \mathrm{G}$ in ratio $1: 1,1: 2,1: 3,2: 1$ and $3: 1$ respectively.

sults show that, the polymer blend at ratio $2: 1$ performed better than all the other blends in extending drug release. For example it released $70 \%$ of the drug in $312 \mathrm{~min}$ (Table 3) compared to the $204 \mathrm{~min}$ for the formulation containing $30 \%$ AEG. The binary blends of AEG and $\mathrm{C} 71 \mathrm{G}$ in the ratio of $2: 1$ and $1: 3$ were better at extending drug release than AEG 
polymer used singly. These formulations are also more economical and more eco friendly than using the synthetic carbopol alone.

Release Mechanism The $n$ values for all the formulations ranged from 0.44 to 0.97 (Table 6). All the formulations except those containing $10 \% \mathrm{C} 71 \mathrm{G}$ had $n$ value greater than 0.5 , indicating that their release mechanism was nonFickian or anomalous $(0.45<n<0.89)$. This implies that release from these formulations was dependent on drug diffusion and polymer relaxation. The correlation coefficients ( $r$ values ranged from 0.85 to $0.99 ; 0.92$ to $0.99,0.96$ to 1.00 for zero order, Higuchi and Ritger-Peppas models respectively) was poor for zero order and this may be due to the drug release mechanism. It was observed during the swelling studies that the matrix tablets undergo significant swelling which was largely dependent on the $\mathrm{pH}$ of the dissolution medium.

\section{CONCLUSION}

In this study, use of polymer blends in the formulation of matrix tablets resulted in better tableting performance when compared to the individual polymer's performance. The results of drug dissolution studies showed improved drug release retardation effects of the polymer blends. Blending a natural gum with a synthetic polymer could achieve equivalent or better performance while being more economical. Generally, blending AEG with $\mathrm{C} 71 \mathrm{G}$ did not alter the drug release mechanism.

\section{REFERENCES}

1) Ravi P. R., Ganga S., Saha R. N., Chem. Pharm. Bull., 56, 518-524 (2008).

2) Joint United Nations Programme on HIV/AIDS (UNAIDS) and World Health Organization (WHO), “AIDS Epidemic Update 2005," Geneva, UNAIDS, Available at: http://www.unaids.org/epi/2005/doc/

3) Richman D., Fischl M. M., Grieco M. H., Gottlieb M. S., Volberding P. A., Laskin O. L., Leedom J. M., Groopman J. E., Mildvan D., Hirsch M. S., Jackson G., Durack D. T., Phil D., Nusinoff-Lehrman S., N. Engl. J. Med., 317, 192-197 (1987).

4) Lewis L. D., Amin S., Civin C. I., Lietman P. S., Hum. Exp. Toxicol., 23, 173-185 (2004)

5) Anthony S. F., Clifford H. L., "Human Immunodeficiency Virus (HIV) Disease, AIDS and Related Disorders," 15th ed., Vol. 2, Part 12, ed. by Braunwald E., Fauci A. S., Kasper D. L., Hauser S. L., Longo D. L. Jameson J. L., McGraw-Hill, New York, 2001, pp. 1852-1913.

6) Betty J. D., "Human Immunodeficiency Virus (HIV) - Antiretroviral Therapy," Section 15, 7th ed., ed. by Herfindal E. T., Gourley D. R., Lippincott Williams \& Wilkins, Philadelphia, 2000, pp. 1555-1582.

7) Laskin O. L., de Miranda P., Blum M. R., J. Infect. Dis., 159, 745-747 (1989).

8) Chitnis S., Mondal D., Agrawal K. C., Life Sci., 12, 967-978 (2002).

9) Chariot P., Drogou I., de Lacroix-Szmania I., Eliezer-Vanerot M. C.,
Chazaud B., Lombès A., Schaeffer A., Zafrani E. S., J. Hepatol., 30, $156-160$ (1999).

10) Re M. C., Bon I., Monari P., Gorini R., Schiavone P., Gibellini D., Placa M., Microbiologica, 26, 405-413 (2003).

11) Vazquez M. J., Perez-Marcos B., Gomez-Amoza J. L., MartinezPacheco R., Souto C., Concheiro A., Drug Dev. Ind. Pharm., 20, 2519-2526 (1992).

12) Varshosaz J., Tavakoli N., Kheirolahi F., AAPS PharmSciTech, 7, Article 24 (2006).

13) Sujja-areevath J., Munday D. L., Cox P. J., Khan K. A., Int. J. Pharm., 139, 53-62 (1996)

14) Emeje M. O., Kunle O. O., Ofoefule S. I., Acta Pharm., 56, 325-335 (2006).

15) Emeje M. O., Kunle O. O., Ofoefule S. I., AAPS PharmSciTech, 7, Article 58 (2006)

16) Emeje M. O., Nwabunike P. I., Isimi C. Y., Kunle O. O., Ofoefule S. I., J. Pharm. Toxicol., 3, 84-92 (2008).

17) Juarez H., Rico G., Villafuerte L., Int. J. Pharm., 216, 115-125 (2001).

18) Emeje M. O., Kunle O. O., J. Nutraceuticals, Medical Functional Foods, 3/4, 147-154 (2004)

19) Conti S., Maggi L., Segale L., OchoaMachiste E., Conte U., Grenier P. Vergnault G., Int. J. Pharm., 333, 136-142 (2007).

20) Emeje M. O., Kunle O. O., Ofoefule S. I., Drug Deliv. Tech., 3 56-61 (2005).

21) Aditya S., Tatavarti K., Mehta A., Larry L., Augsburger, Hoag S. W. J. Pharm. Sci., 93, 2319-2331 (2004).

22) Grabovac V., Guggi D., Bernkop-Schnürch A., Adv. Drug Deliv. Rev., 57, 1713-1723 (2005)

23) Bommareddya G. S., Paker-Leggs S., Saripella K. K., Neaua S. H., Int. J. Pharm., 321, 62-71 (2006).

24) Emeje M. O., Franklin-Ude P. I., Ofoefule S. I., J. Pharm. Toxicol., 2, 646-652 (2007)

25) Emeje M. O., Isimi C. Y., Kunle O. O., African J. Pharm. Pharmcol., 2,001-006 (2008)

26) Franklin-Ude P. I., Emeje M. O., Ofoefule S. I., J. Pharm. Toxicol., 3, 53-63 (2008)

27) Parojcic J., Duric Z., Jovanovic M., Ibric S., Drug Deliv., 11, 59-65 (2004).

28) Korsenmeyer R. W., Peppas N. A., "Macromolecular and Modeling Aspects of Swelling-Controlled Systems," ed. by Mansdorf S. Z., Roseman T. J., Marcel Dekker Inc., New York, 1983, p. 77.

29) Velasco M. V., Ford J. L., Rowe P., Rajabi-Siahboomi A. R., J. Controlled Release, 57, 75-85 (1999).

30) Ritger P. L., Peppas N. A., J. Controlled Release, 5, $37-42$ (1987).

31) Nasipuri R. N., Igwilo C. I., Brown S. A., Kunle O. O., J. Pharm. Res. Dev., 1, 22-28 (1996).

32) Nasipuri R. N., Igwilo C. I., Brown S. A., Kunle O. O., J. Phytomed. Ther., 1, 22-88 (1999).

33) Nasipuri R. N., Igwilo C. I., Brown S. A., Kunle O. O., J. Phytomed. Ther., 2, 27-34 (1999).

34) Emeje M. O., Isimi C. Y., Kunle O. O., Continental J. Pharm. Sci., 3 , 1-6 (2007).

35) Kalu V. D., Odeniyi M. A., Jaiyeoba K. T., Arch. Pharmacol. Res., 30, 884-889 (2007).

36) Ohwoavworhua F. O., Adelakun T. A., Tropical J. Pharm. Res., 4, 1-7 (2005).

37) Nokhodchi A., Rubistein M. H., Ford J. L., Int. J. Pharm., 126, 189 197 (1995). 